\title{
ARBOVIRUSES IN NSW, 1991 TO 1999
}

\section{David Muscatello and Jeremy McAnulty} Communicable Diseases Surveillance and Control Unit

Arthropod-borne viruses, or arboviruses, are transmitted mainly by mosquitoes and ticks. Worldwide, more than 100 arboviruses have been recognised as causing disease in humans, representing a subset of an even greater number that circulate in other species. Arboviruses are believed to migrate among animal species (zoonosis), including between animals and humans. ${ }^{1}$ Arboviral diseases are notifiable to public health units (PHUs) in NSW. This article reports available data on the occurrence of notified arboviral diseases in NSW for the period 19911999.

Arboviral diseases present as four main syndromes in humans:

\section{TABLE 8}

NSW RESIDENTS NOTIFIED WITH ROSS RIVER OR BARMAH FOREST VIRUS INFECTION BY YEAR, NSW, 1991-1999

\begin{tabular}{|lcc|}
\hline Year of onset & Ross River virus & Barmah Forest virus \\
\hline 1991 & 292 & 6 \\
1992 & 316 & 6 \\
1993 & 592 & 25 \\
1994 & 324 & 40 \\
1995 & 234 & 271 \\
1996 & 1,021 & 172 \\
1997 & 1550 & 185 \\
1998 & 582 & 133 \\
1999 & 952 & 246 \\
\hline Total & 5,863 & $\mathbf{1 , 0 8 4}$ \\
\hline
\end{tabular}

\section{FIGURE 4}

NOTIFICATIONS OF ROSS RIVER AND BARMAH FOREST VIRUSES, NSW, 1995-1999, BY MONTH OF ONSET

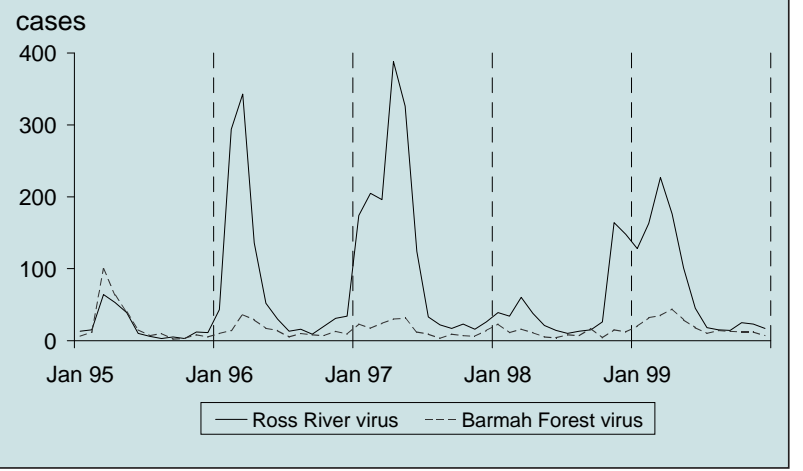

- acute central nervous system disease, which can span a severity range that includes mild meningitis to fatal encephalitis;

- haemorrhagic fevers, which can lead to liver damage and death;

- acute uncomplicated fever which may proceed to the more severe syndromes above;

- polyarthritis (multiple joint inflammation) and rash, with or without fever. ${ }^{1}$

The most potentially severe arboviruses recognised in Australia are from the flaviviridae family and include the Murray Valley encephalitis and Kunjin viruses, which can cause encephalitis and have been reported in parts of northern Australia. Dengue virus, which can cause haemorrhagic fever, and Japanese encephalitis, have also been reported but are not believed to be endemic to Australia. The more common Ross River and Barmah Forest viruses are from the togaviridae family and lead to milder disease such as polyarthritis and rash. Ross River virus infection has been reported in all states of Australia, and Barmah Forest virus infection has been reported in all states except Tasmania. ${ }^{1,2}$

\section{METHODS}

Under the NSW Public Health Act 1991, all laboratories must notify suspected cases of arboviral diseases to the local PHU. Selected severe arboviral infections must be notified by hospitals. ${ }^{3}$ PHU staff record details of cases on a confidential statewide database. We selected cases of arboviral infection notified to PHUs for the years 1991 to 1999 inclusive. Only cases notified between 1995 and 1999 were used in the analysis of case characteristics due to the possibility of under-reporting in earlier years. Under-reporting was likely to be due to a lack of awareness in the community about arboviruses and the relatively recent availability of serological tests for Barmah Forest virus. Incidence rates were calculated using the average of the estimated mid-year population for each of the years 1995 to 1999.

\section{RESULTS}

During the period 1991-1999, 5,863 cases of Ross River virus infection and 1,084 cases of Barmah Forest virus infection were reported among NSW residents. Ross River virus infection was most frequently reported in 1997 $(1,550)$ and Barmah Forest in 1995 (234) (Table 8). There were 119 reports of Dengue virus infection, two reports of Kunjin virus infection, and one report of Murray Valley encephalitis. The case of Murray Valley encephalitis is known to have been acquired during travel outside of NSW, as is likely for Dengue virus infections. There were 


\begin{tabular}{|c|c|c|c|c|}
\hline \multicolumn{5}{|c|}{$\begin{array}{l}\text { CHARACTERISTICS OF NSW RESIDENTS NOTIFIED WITH ROSS RIVER VIRUS OR } \\
\text { BARMAH FOREST VIRUS INFECTIONS, 1995-1999 }\end{array}$} \\
\hline \multirow[b]{2}{*}{ Case characteristics } & \multicolumn{2}{|c|}{ Ross River virus } & \multicolumn{2}{|c|}{ Barmah Forest virus } \\
\hline & $\begin{array}{l}\text { Cases } \\
\text { (\% total) }\end{array}$ & $\begin{array}{l}\text { Average annual } \\
\text { rate per } 100,000\end{array}$ & $\begin{array}{l}\text { Cases } \\
(\% \text { total) }\end{array}$ & $\begin{array}{c}\text { Average annual rate } \\
\text { per } 100,000\end{array}$ \\
\hline \multicolumn{5}{|l|}{ Residence } \\
\hline Sydney area & $463(11)$ & 2.5 & $37(4)$ & 0.2 \\
\hline Other NSW & $3,876(89)$ & 30.1 & $970(96)$ & 7.5 \\
\hline \multicolumn{5}{|l|}{ Sex } \\
\hline Male & $2,160(50)$ & 13.9 & $561(56)$ & 3.6 \\
\hline Female & $2,167(50)$ & 13.7 & $442(44)$ & 2.8 \\
\hline Unknown & $12(0)$ & & $4(0)$ & \\
\hline \multicolumn{5}{|l|}{ Age group } \\
\hline$<15$ & $150(3)$ & 2.3 & $33(3)$ & 0.5 \\
\hline $15-24$ & $414(10)$ & 9.4 & $73(7)$ & 1.7 \\
\hline $25-34$ & 806 (19) & 16.7 & $136(14)$ & 2.8 \\
\hline $35-49$ & $1,568(36)$ & 22.5 & $420(42)$ & 6.0 \\
\hline $50-64$ & $997(23)$ & 21.7 & $248(25)$ & 5.4 \\
\hline$>64$ & $403(9)$ & 10.2 & $97(10)$ & 2.4 \\
\hline Unknown & $1(0)$ & & $0(0)$ & \\
\hline Total & $4,339(100)$ & 13.8 & $1,007(100)$ & 3.2 \\
\hline
\end{tabular}

no reports of Japanese encephalitis during the period. There were 178 reports of other or unspecified arboviral infections.

The average annual incidence of Ross River virus infection for the period was 13.8 per 100,000 persons, and of Barmah Forest virus infection 3.2 per 100,000. A distinct seasonal pattern is evident for both diseases, with peaks in late summer and autumn (Figure 4).

The incidence of Ross River virus infection increased with distance from Sydney, which had a reported rate of infection of 2.5/100,000. The highest rates were reported in residents of the Far West Area Health Service (114.4/ 100,000, Figure 5). The distribution of Barmah Forest virus infection was different, with low incidence areas including Sydney $(0.2 / 100,000)$ into the Central Coast $(0.3 / 100,000)$, Mid Western $(0.5 / 100,000)$, and Hunter $(1.0 / 100,000)$ Areas. The highest incidence of Barmah Forest virus infection was in the Mid North Coast (28.2/ $100,000)$ and Northern Rivers $(22.0 / 100,000)$ Areas (Figure 6).

The age distribution of the cases was similar between the two diseases, with rates of reporting increasing with age up to the highest rates in persons aged 35-49 years (Ross River: 22.5/100,000, Barmah Forest: 6.0/100,000), and then declining in older age groups (Table 9). Ross River virus infection was reported equally frequently in men and women. However, there was a slightly higher rate of reporting of Barmah Forest virus infection in men (Table 9).

There was only one reported death associated with Ross River virus infection over the nine year period, and this was in an older person who was admitted to hospital. The virus was unlikely to be the underlying cause of death.

\section{DISCUSSION}

Ross River virus infection is frequently reported in NSW, and occurs with increasing frequency with distance from the Sydney metropolitan area. PHUs report that illness reported in Sydney residents was usually acquired during travel to rural areas. Barmah Forest is less common in NSW, but occurs most frequently in the northern coastal regions of the State. Both diseases most commonly affect people of middle age and occur at similar rates in both sexes. The seasonal pattern is marked, with notifications, particularly of Ross River virus infection, increasing dramatically in late summer and autumn.

The reports of Dengue virus infection are most likely to have been in travellers, since the mosquito vector for this infection (Aedes aegypti) does not reside in NSW. ${ }^{2}$

The low reporting of Barmah Forest virus infection in the years 1991-1994 may be due to the relatively recent availability of a serological test for the disease. Levels of media interest in these diseases may also influence rates of reporting. 


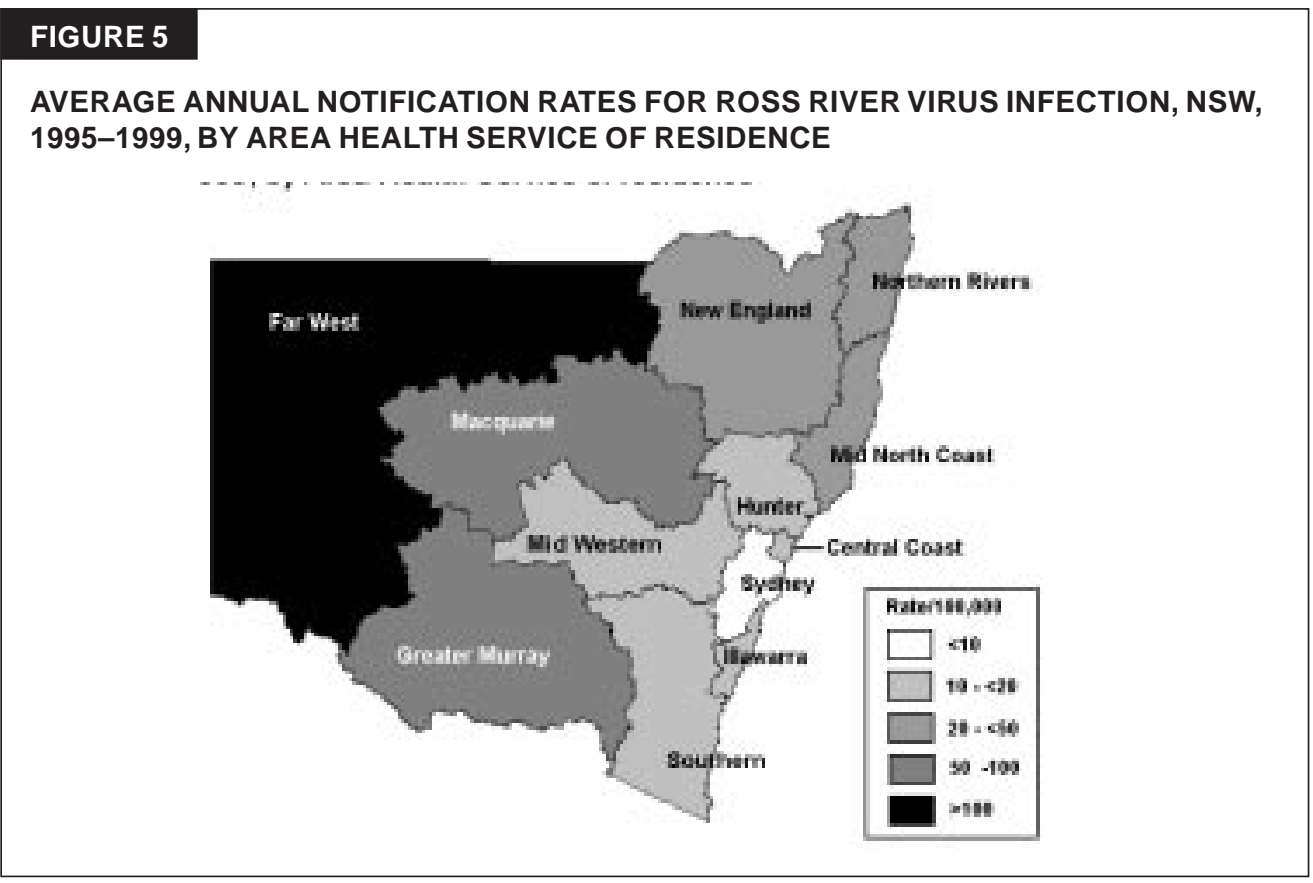

\section{FIGURE 6}

AVERAGE ANNUAL NOTIFICATION RATES FOR BARMAH FOREST VIRUS INFECTION, NSW, 1995-1999, BY AREA HEALTH SERVICE OF RESIDENCE

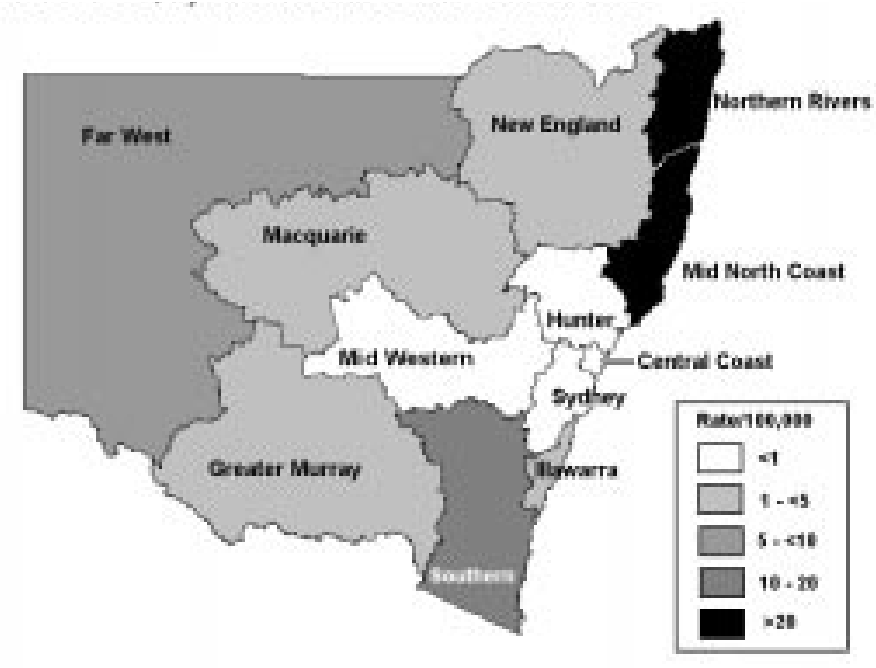

The relatively high rates of reporting of arboviral infections in rural areas indicate a need for prevention messages to be targeted at rural residents and visitors to rural areas, particularly in the high-risk seasons of summer and autumn. Residents of, and visitors to, the western and north western regions and the northern coastal areas of NSW should be especially cautious as they are most at risk of acquiring Ross River or Barmah Forest virus infections.

\section{REFERENCES}

1. Chin J (editor). Control of Communicable Diseases Manual. 17th Edition. Washington: American Public Health Association, 2000.

2. Mackenzie JS, Broom AK, Hall RA, Johansen CA, Lindsay MD, Phillips DA, et al. Arboviruses in the Australian region, 1990 to 1998. Comm Dis Intell 1998; 22: 93-100.

3. NSW Department of Health. Notification of diseases under the Public Health Act 1991 (Departmental Circular 98/94). Sydney: NSW Department of Health, 1998. it: 